\title{
Complexation of $\mathrm{Pb}$ (II) by Chloride Ions in Aqueous Solutions
}

\author{
Robert H. Byrne $\cdot$ Wensheng Yao $\cdot$ Yanxin Luo $\cdot$ Frank J. Millero
}

Received: 20 January 2010/Accepted: 24 February 2010/Published online: 19 March 2010

(C) The Author(s) 2010. This article is published with open access at Springerlink.com

\begin{abstract}
Lead chloride formation constants at $25^{\circ} \mathrm{C}$ were derived from analysis of previous spectrophotometrically generated observations of lead speciation in a variety of aqueous solutions $\left(\mathrm{HClO}_{4}-\mathrm{HCl}\right.$ and $\mathrm{NaCl}-\mathrm{NaClO}_{4}$ mixtures, and solutions of $\mathrm{MgCl}_{2}$ and $\mathrm{CaCl}_{2}$ ). Specific interaction theory analysis of these formation constants produced coherent estimates of (a) $\mathrm{PbCl}^{+}, \mathrm{PbCl}_{2}^{0}$, and $\mathrm{PbCl}_{3}^{-}$formation constants at zero ionic strength, and (b) well-defined depictions of the dependence of these formation constants on ionic strength. Accompanying examination of a recent IUPAC critical assessment of lead formation constants, in conjunction with the spectrophotometrically generated formation constants presented in this study, revealed significant differences among various subsets of the IUPAC critically selected data. It was found that these differences could be substantially reduced through reanalysis of the formation constant data of one of the subsets. The resulting revised lead chloride formation constants are in good agreement with the formation constants derived from the earlier spectrophotometrically generated data. Combining these data sets provides an improved characterization of lead chloride complexation over a wide range of ionic strengths:
\end{abstract}

$$
\begin{gathered}
\log _{\mathrm{Cl}} \beta_{1}=1.491-2.04 I^{1 / 2}\left(1+1.5 I^{1 / 2}\right)^{-1}+0.238 I \\
\log _{\mathrm{Cl}} \beta_{2}=2.062-3.06 I^{1 / 2}\left(1+1.5 I^{1 / 2}\right)^{-1}+0.369 I \\
\log _{\mathrm{Cl}} \beta_{3}=1.899-3.06 I^{1 / 2}\left(1+1.5 I^{1 / 2}\right)^{-1}+0.439 I .
\end{gathered}
$$

\footnotetext{
R. H. Byrne $(\bowtie) \cdot$ W. Yao

College of Marine Science, University of South Florida, 140 7th Ave. South, St, Petersburg, FL 33701, USA

e-mail: byrne@marine.usf.edu

Y. Luo

Pall Corporation, 25 Harbor Park Dr., Port Washington, NY 11050, USA

F. J. Millero

Rosenstiel School of Marine and Atmospheric Science, University of Miami, 4600 Rickenbacker Causeway, Miami, FL 33149, USA
} 
Keywords Lead chloride formation constants $\cdot$ Lead speciation in natural waters

\section{Introduction}

A recent International Union of Pure and Applied Chemistry (IUPAC) review and analysis of $\mathrm{Pb}$ (II) complexation by inorganic ligands (Powell et al. 2009) noted the importance of both lead chloride and lead carbonate species in saline natural waters and concluded that "There is scope for additional careful measurements in the $\mathrm{Pb}^{2+}-\mathrm{CO}_{3}{ }^{2-}-\mathrm{Cl}^{-}$system." The need for additional careful measurements of lead carbonate complexation is driven by a paucity of high-quality data. In contrast, lead chloride complexation data are relatively abundant, but significant ambiguities in the interpretation of these data merit further attention.

Powell et al. (2009) provides a compilation of critically selected lead chloride stability constants based on 88 observations of $\log { }_{\mathrm{Cl}} \beta_{1}, \log _{\mathrm{Cl}} \beta_{2}$, and $\log _{\mathrm{Cl}} \beta_{3}$ at $25^{\circ} \mathrm{C}$, where

$$
\begin{aligned}
\mathrm{Cl}_{1} \beta_{1} & =\left[\mathrm{PbCl}^{+}\right]\left[\mathrm{Pb}^{2+}\right]^{-1}\left[\mathrm{Cl}^{-}\right]^{-1} \\
\mathrm{Cl}_{\mathrm{Cl}} \beta_{2} & =\left[\mathrm{PbCl}_{2}^{0}\right]\left[\mathrm{Pb}^{2+}\right]^{-1}\left[\mathrm{Cl}^{-}\right]^{-2} \\
\mathrm{Cl} & \beta_{3}=\left[\mathrm{PbCl}_{3}^{-}\right]\left[\mathrm{Pb}^{2+}\right]^{-1}\left[\mathrm{Cl}^{-}\right]^{-3} .
\end{aligned}
$$

The ionic strength dependencies of $\log { }_{\mathrm{Cl}} \beta_{1}, \log { }_{\mathrm{Cl}} \beta_{2}$, and $\log _{\mathrm{Cl}} \beta_{3}$ were characterized via regression analyses (Powell et al. 2009) using the following specific interaction theory (SIT) function:

$$
\log _{\mathrm{Cl}} \beta_{\mathrm{n}}+\left(\Delta \mathrm{z}^{2}\right) \mathrm{D}=\log _{\mathrm{Cl}} \beta_{n}^{0}+\mathrm{C}_{\mathrm{n}} I
$$

where ${ }_{\mathrm{Cl}} \beta_{\mathrm{n}}$ is defined in Eqs. $1-3(n=1,2,3), \mathrm{Cl}_{\mathrm{Cl}} \beta_{n}^{0}$ is a stability constant at zero ionic strength, $\mathrm{C}_{n}$ is a regression constant, $\mathrm{D}$ is given as

$$
\mathrm{D}=0.510 I^{1 / 2}\left(1+1.5 I^{1 / 2}\right)^{-1}
$$

and $\Delta \mathrm{z}^{2}$ is the sum of the squared reactant charges minus the sum of the squared product charges for the following equilibria appropriate to Eqs. 1-3:

$$
\begin{gathered}
\mathrm{Pb}^{2+}+\mathrm{Cl}^{-} \leftrightarrow \mathrm{PbCl}^{+} \\
\mathrm{Pb}^{2+}+2 \mathrm{Cl}^{-} \leftrightarrow \mathrm{PbCl}_{2}^{0} \text { and } \\
\mathrm{Pb}^{2+}+3 \mathrm{Cl}^{-} \leftrightarrow \mathrm{PbCl}_{3}^{-} .
\end{gathered}
$$

In the present work, the investigation of Powell et al. (2009) is used as a starting point for further refinement of lead chloride speciation depictions in natural waters. The IUPAC data set is divided into four components, and each of these component subsets is assessed via Eqs. 4 and 5. Three component data sets consist of works that contain formation constants at multiple ionic strengths (Mironov et al. 1963; Bendiab et al. 1982; and a subset of Luo and Millero 2007); the fourth component data set is constructed (Powell et al. 2009) from data in eight publications that each present formation constant data at a single ionic strength.

Additional formation constant data not utilized in the IUPAC SIT analyses are also here examined to provide further perspectives on the behavior of lead chloride complexation. 
We use measurements of $\log { }_{\mathrm{Cl}} \beta_{1}, \log { }_{\mathrm{Cl}} \beta_{2}$, and $\log { }_{\mathrm{Cl}} \beta_{3}$ obtained by Luo and Millero (2007) at ionic strengths between 0.13 and 0.44 molal to refine the Powell et al. (2009) SIT analysis of a portion of the Luo and Millero (2007) data. We also use an extensive set of $\log { }_{\mathrm{Cl}} \beta_{1}, \log \mathrm{Cl}_{2} \beta_{2}$, and $\log \mathrm{Cl}_{3} \beta_{3}$ values obtained in $\mathrm{HClO}_{4}-\mathrm{HCl}$ mixtures, $\mathrm{NaCl}-\mathrm{NaClO}_{4}$ mixtures, $\mathrm{MgCl}_{2}$ solutions, and $\mathrm{CaCl}_{2}$ solutions, all at $25^{\circ} \mathrm{C}$ (Byrne and Miller 1984), to generate additional SIT assessments of lead chloride complexation behavior. The speciation data of Byrne and Miller (1984) combined with the data of Luo and Millero (2007) provide an improved depiction of lead chloride complexation over a wide range of ionic strengths.

\section{Methods}

The formation constants reported in Byrne and Miller (1984) and Luo and Millero (2007) were obtained using the spectrophotometric procedures described in Byrne et al. (1981). Observations of the absorbance $\left({ }_{\lambda} \mathrm{A}\right)$ of $\mathrm{Pb}$ (II) were obtained in $1 \mathrm{M} \mathrm{HCl}-\mathrm{HClO}_{4}$ mixtures at $25^{\circ} \mathrm{C}$. Absorbance observations were then deconvoluted to produce (a) estimates of $\log$ ${ }_{\mathrm{Cl}} \beta_{1}, \log { }_{\mathrm{Cl}} \beta_{2}$, and $\log _{\mathrm{Cl}} \beta_{3}$ appropriate at $1 \mathrm{M}$ ionic strength, and (b) molar absorbance values $\left({ }_{\lambda} \varepsilon\right)$ for $\mathrm{Pb}^{2+}, \mathrm{PbCl}^{+}, \mathrm{PbCl}_{2}^{0}$, and $\mathrm{PbCl}_{3}^{-}$at nineteen wavelengths (for each chemical species) between 210 and $300 \mathrm{~nm}$. Subsequently, $\mathrm{Pb}$ (II) absorbance spectra were obtained in mixtures of $\mathrm{HClO}_{4}-\mathrm{HCl}, \mathrm{NaClO}_{4}-\mathrm{NaCl}, \mathrm{MgCl}_{2}$, and $\mathrm{CaCl}_{2}$. The absorbance spectra obtained using each mixture at a constant concentration of chloride ion $\left(25^{\circ} \mathrm{C}\right)$ were analyzed using the following equation at nineteen wavelengths $(\lambda)$ :

$$
{ }_{\lambda} \mathrm{A}={ }_{\lambda} \varepsilon_{0}\left[\mathrm{~Pb}^{2+}\right]+{ }_{\lambda} \varepsilon_{1}\left[\mathrm{PbCl}^{+}\right]+{ }_{\lambda} \varepsilon_{2}\left[\mathrm{PbCl}_{2}^{0}\right]+{ }_{\lambda} \varepsilon_{3}\left[\mathrm{PbCl}_{3}^{-}\right] .
$$

The results of this analysis were then compiled (Byrne and Miller 1984) in the form of mole fractions $\left(\left[\mathrm{Pb}^{2+}\right] /[\mathrm{Pb}]_{\mathrm{T}},\left[\mathrm{PbCl}^{+}\right] /[\mathrm{Pb}]_{\mathrm{T}},\left[\mathrm{PbCl}_{2}^{0}\right] /[\mathrm{Pb}]_{\mathrm{T}}\right.$ etc. $)$, where

$$
[\mathrm{Pb}]_{\mathrm{T}}=\left[\mathrm{Pb}^{2+}\right]+\left[\mathrm{PbCl}^{+}\right]+\left[\mathrm{PbCl}_{2}^{0}\right]+\left[\mathrm{PbCl}_{3}^{-}\right] \text {. }
$$

The mole fractions and associated statistical uncertainties determined at each chloride concentration then allowed direct calculation of lead chloride formation constants and associated uncertainties via Eqs. 1-3. The methods used by Byrne et al. (1981) and Byrne and Miller (1984) to derive lead chloride complexation constants are also described in detail in the work of Luo and Millero (2007) wherein observations were extended to a range of temperatures and high ionic strengths.

\section{Results and Discussion}

A summary of the SIT fits obtained using the data of Powell et al. (2009) is shown in Table 1. The range of $\log \mathrm{Cl}_{n} \beta_{n}^{0}$ values for the four component data sets in Table 1 is as follows: $1.347 \leq \log _{\mathrm{Cl}} \beta_{1}^{0} \leq 1.657,1.999 \leq \log _{\mathrm{Cl}} \beta_{2}^{0} \leq 2.222$, and $1.758 \leq \log _{\mathrm{Cl}} \beta_{3}^{0} \leq 2.509$.

The data of Byrne and Miller (1984; BM84) were not used in the evaluation of Powell et al. (2009) because these data were reported in the form of mole fractions (i.e., $\left[\mathrm{Pb}^{2+}\right] /[\mathrm{Pb}]_{\mathrm{T}},\left[\mathrm{PbCl}^{+}\right] /[\mathrm{Pb}]_{\mathrm{T}},\left[\mathrm{PbCl}_{2}^{0}\right] /[\mathrm{Pb}]_{\mathrm{T}}$, and $\left[\mathrm{PbCl}_{3}^{-}\right] /[\mathrm{Pb}]_{\mathrm{T}}$ at well-defined chloride ion concentrations, $\left[\mathrm{Cl}^{-}\right]$, and ionic strength, $I$ ) rather than as explicit stability constants (Eqs. 1-3). Formation constants calculated from the $\mathrm{Pb}$ (II) speciation characterizations of BM84 are shown in Appendix Tables 5, 6, 7, 8, and a summary of the slopes $\left(\mathrm{C}_{n}\right)$ and 
Table 1 Slopes $\left(\mathrm{C}_{n}\right)$ and intercepts $\left(\log { }_{\mathrm{Cl}} \beta_{n}^{0}\right)$ in Eq. 4 for the overall data set (IUPAC) and the four component subsets (IUPAC8s, B82, M63, and LM07p)

\begin{tabular}{llllll}
\hline & IUPAC & IUPAC8s & B82 & M63 & LM07p \\
\hline $\mathrm{C}_{1}$ & $0.145 \pm 0.011$ & $0.103 \pm 0.023$ & $0.113 \pm 0.058$ & $0.159 \pm 0.023$ & $0.182 \pm 0.020$ \\
$\mathrm{C}_{2}$ & $0.262 \pm 0.017$ & $0.259 \pm 0.031$ & $0.188 \pm 0.086$ & $0.265 \pm 0.036$ & $0.297 \pm 0.030$ \\
$\mathrm{C}_{3}$ & $0.315 \pm 0.029$ & $0.178 \pm 0.055$ & $0.265 \pm 0.216$ & $0.317 \pm 0.072$ & $0.394 \pm 0.044$ \\
$\log _{\mathrm{Cl}} \beta_{1}^{0}$ & $1.503 \pm 0.032$ & $1.657 \pm 0.074$ & $1.540 \pm 0.083$ & $1.509 \pm 0.058$ & $1.347 \pm 0.067$ \\
$\log _{\mathrm{Cl}} \beta_{2}^{0}$ & $2.111 \pm 0.047$ & $1.999 \pm 0.103$ & $2.222 \pm 0.125$ & $2.201 \pm 0.094$ & $2.034 \pm 0.094$ \\
$\log _{\mathrm{Cl}} \beta_{3}^{0}$ & $2.040 \pm 0.093$ & $2.509 \pm 0.196$ & $2.026 \pm 0.373$ & $2.147 \pm 0.211$ & $1.758 \pm 0.152$ \\
\hline
\end{tabular}

All fits were weighted fits obtained using the data and weights of Powell et al. (2009)

IUPAC—Original IUPAC data (Powell et al. 2009)

IUPAC8s-IUPAC component data set compiled from eight publications, each reporting lead chloride formation constants at a single ionic strength; excludes Luo and Millero (2007), Bendiab et al. (1982), and Mironov et al. (1963)

B82 Bendiab et al. (1982)

M63 Mironov et al. (1963)

LM07p - Subset of Luo and Millero (2007) dataset, as was used in the IUPAC analysis (i.e., partial data set that excludes six observations at $I<0.5$ molal)

Table 2 Slopes $\mathrm{C}_{n}$ and intercepts $\log _{\mathrm{Cl}} \beta_{n}^{0}$ in Eq. 4 obtained from Byrne and Miller (1984) data in different media

\begin{tabular}{lllll}
\hline & $\mathrm{HCl}-\mathrm{HClO}_{4}$ & $\mathrm{NaCl}-\mathrm{NaClO}_{4}$ & $\mathrm{CaCl}_{2}$ & $\mathrm{MgCl}_{2}$ \\
\hline $\mathrm{C}_{1}$ & $0.229 \pm 0.002$ & $0.200 \pm 0.002$ & $0.141 \pm 0.002$ & $0.161 \pm 0.002$ \\
$\mathrm{C}_{2}$ & $0.349 \pm 0.004$ & $0.335 \pm 0.003$ & $0.228 \pm 0.004$ & $0.249 \pm 0.004$ \\
$\mathrm{C}_{3}$ & $0.383 \pm 0.010$ & $0.473 \pm 0.012$ & $0.299 \pm 0.024$ & $0.306 \pm 0.020$ \\
$\log _{\mathrm{Cl}} \beta_{1}^{0}$ & $1.505 \pm 0.002$ & $1.505 \pm 0.001$ & $1.517 \pm 0.002$ & $1.514 \pm 0.002$ \\
$\log _{\mathrm{Cl}} \beta_{2}^{0}$ & $2.092 \pm 0.003$ & $2.073 \pm 0.002$ & $2.074 \pm 0.004$ & $2.070 \pm 0.004$ \\
$\log _{\mathrm{Cl}} \beta_{3}^{0}$ & $1.979 \pm 0.008$ & $1.883 \pm 0.010$ & $1.885 \pm 0.021$ & $1.885 \pm 0.019$ \\
\hline
\end{tabular}

All fits were weighted fits based on the uncertainties reported in Appendix Tables 5, 6, 7, 8

intercepts $\left(\log _{\mathrm{Cl}} \beta_{n}^{0}\right)$ obtained in SIT fits of these data are given in Table 2. The ranges of $\log { }_{\mathrm{Cl}} \beta_{n}^{0}$ values for all four BM84 experimental media (Table 2) are $1.505 \leq \log _{\mathrm{Cl}} \beta_{1}^{0} \leq$ $1.517,2.070 \leq \log _{\mathrm{Cl}} \beta_{2}^{0} \leq 2.092$, and $1.883 \leq \log _{\mathrm{Cl}} \beta_{3}^{0} \leq 1.979$. These results are closely similar to the results obtained in the analysis of Powell et al. (2009), which are presented in the first column (IUPAC) of Table 1. In contrast, given that the methods used by Byrne and Miller (1984) and Luo and Millero (2007) are closely similar, it was initially puzzling that the Table 2 results differ substantially from the results shown in the last column (LM07p) of Table 1.

Because the methods of Byrne et al. (1981), Byrne and Miller (1984), and Luo and Millero (2007) are essentially identical, it is reasonable to suppose that the observed differences between the results shown in Table 2 (BM84) and Table 1 (LM07p) are a reflection of differences in the molar absorptivities produced in the two studies. Figure 1 shows the molar absorptivities obtained by Luo and Millero at four temperatures. The relative magnitudes of the molar absorptivities of $\mathrm{PbCl}^{+}$and $\mathrm{PbCl}_{2}^{0}$ have an irregular progression with increasing temperature. At $15.1^{\circ} \mathrm{C}$, the molar absorptivity of $\mathrm{PbCl}_{2}^{0}$ is 

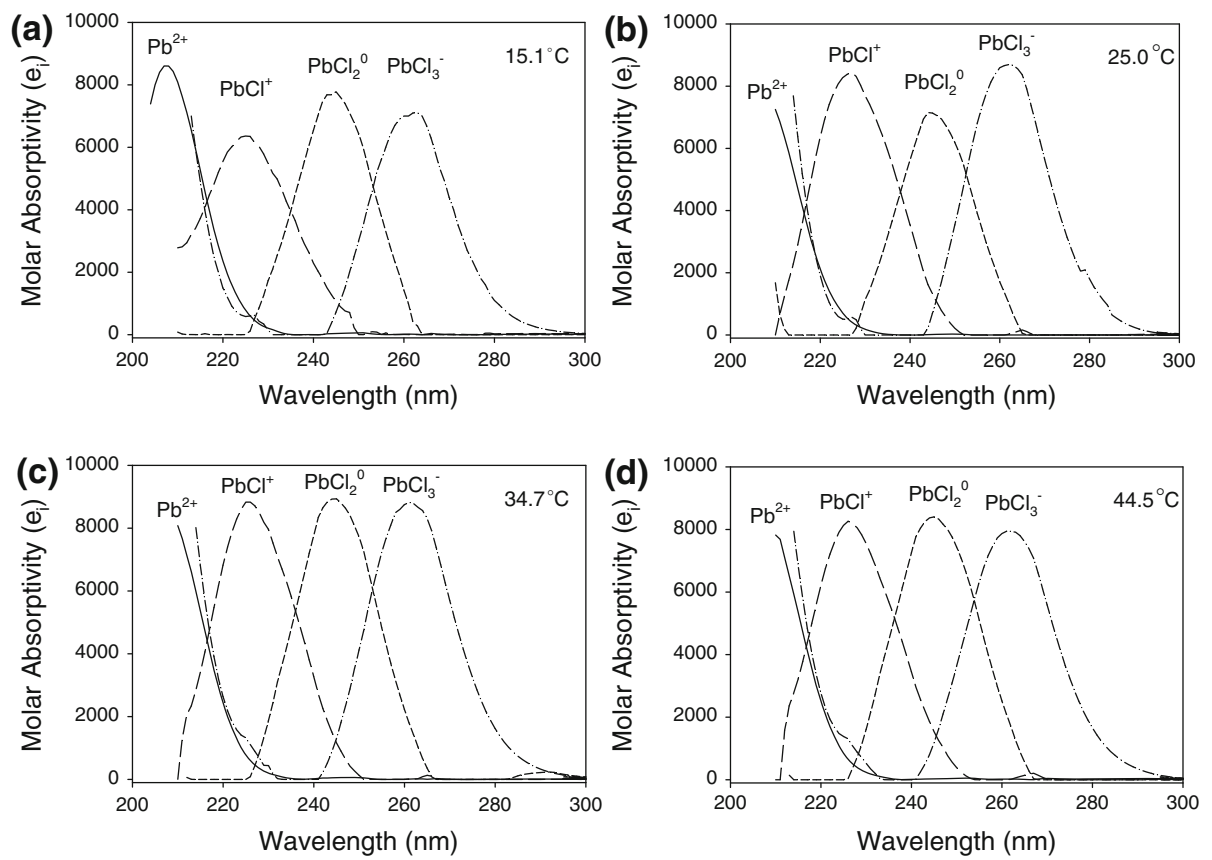

Fig. 1 Molar absorptivities obtained by Luo and Millero (2007) at four temperatures (15.1, 25.0, 34.7, and $\left.44.5^{\circ} \mathrm{C}\right)$

much larger than that of $\mathrm{PbCl}^{+}$while the opposite is true at $25.0^{\circ} \mathrm{C}$. In contrast, at 34.7 and $44.5^{\circ} \mathrm{C}$, the molar absorptivities obtained for each species of $\mathrm{Pb}(\mathrm{II})$ are quite similar. The molar absorptivities of each species (i.e., the relative magnitudes of $\lambda_{2} \varepsilon_{0}, \lambda \varepsilon_{1}, \lambda \varepsilon_{2}$, and ${ }_{\lambda} \varepsilon_{3}$ ) should exhibit small systematic changes over such a small range of temperature. Consequently, as an alternative interpretation of the Luo and Millero (2007) data, it is reasonable

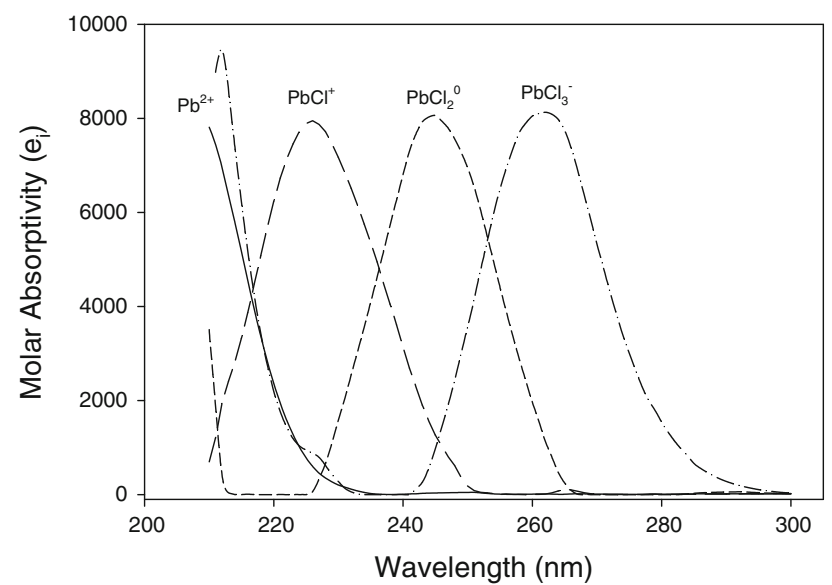

Fig. 2 Average values of the $\mathrm{Pb}$ (II) molar absorptivities obtained at 15.1, 25.0, and $34.7^{\circ} \mathrm{C}$ (Luo and Millero 2007) 
to propose that the average of the molar absorptivities obtained at $15.1,25.0$, and $34.7^{\circ} \mathrm{C}$ (i.e., $25.0 \pm 10^{\circ} \mathrm{C}$ ) would provide a better assessment of $25.0^{\circ} \mathrm{C}$ molar absorptivities than do the molar absorptivities obtained in a single experiment at $25.0^{\circ} \mathrm{C}$. An average of the $\mathrm{Pb}$ (II) molar absorptivities obtained by averaging the results obtained at these three temperatures is shown in Fig. 2. These results are quite similar to those shown in Fig. 1 at 34.7 and $44.5^{\circ} \mathrm{C}$, indicating that the variations in molar absorptivities obtained at 15.1 and $25.0^{\circ} \mathrm{C}$ largely cancel in the averaging process. Consequently, Fig. 2 should be considered as the most appropriate depiction of the molar absorptivities of $\mathrm{Pb}^{2+}, \mathrm{PbCl}^{+}, \mathrm{PbCl}_{2}^{0}$, and $\mathrm{PbCl}_{3}^{-}$over the small range of temperature $\left(\Delta \mathrm{T} \sim 20^{\circ} \mathrm{C}\right)$ between 15.1 and $34.7^{\circ} \mathrm{C}$.

The averaged molar absorptivity results (Fig. 2) were used (via Eqs. 9 and 10) to redetermine $\log _{\mathrm{Cl}} \beta_{\mathrm{n}}$ values in the experiments of Luo and Millero (Table 3; Fig. 3a, b, c). These revised results and the $\mathrm{NaCl}-\mathrm{NaClO}_{4}$ results of Byrne and Miller (1984; Table 2) are in excellent accord (Fig. 3d, e, f). As such, our recommended characterization of the ionic strength dependence of lead chloride formation constants at $25^{\circ} \mathrm{C}$, based on the combined data in Table 3 and Appendix $1\left(\mathrm{NaCl}-\mathrm{NaClO}_{4}\right)$, is as follows (Fig. 3d, e, f):

$$
\begin{aligned}
& \log _{\mathrm{Cl}} \beta_{1}+2.04 I^{1 / 2}\left(1+1.5 I^{1 / 2}\right)^{-1}=1.491+0.238 I \\
& \log _{\mathrm{Cl}} \beta_{2}+3.06 I^{1 / 2}\left(1+1.5 I^{1 / 2}\right)^{-1}=2.062+0.369 I \\
& \log _{\mathrm{Cl}} \beta_{3}+3.06 I^{1 / 2}\left(1+1.5 I^{1 / 2}\right)^{-1}=1.899+0.439 I
\end{aligned}
$$

\section{Conclusions}

The formation constants summarized by Eqs. 11-13, which are based on the combined results of Byrne and Miller (1984; BM84) + Luo and Millero (2007—revised; LM07r),

Table 3 Recalculated formation constants of Luo and Millero (2007) using the average of molar absorptivity results obtained at $15.1,25.0$, and $34.7^{\circ} \mathrm{C}$

\begin{tabular}{llll}
\hline Ionic strength & $\log \beta_{1}$ & $\log \beta_{2}$ & $\log \beta_{3}$ \\
\hline 0.131 & 1.012 & 1.374 & 1.300 \\
0.180 & 0.980 & 1.324 & 1.193 \\
0.240 & 0.970 & 1.300 & 1.143 \\
0.320 & 0.938 & 1.252 & 1.079 \\
0.380 & 0.950 & 1.266 & 1.099 \\
0.440 & 0.977 & 1.293 & 1.139 \\
0.500 & 0.983 & 1.299 & 1.140 \\
0.740 & 0.951 & 1.269 & 1.142 \\
1.120 & 0.917 & 1.249 & 1.118 \\
1.790 & 0.983 & 1.362 & 1.300 \\
2.510 & 1.047 & 1.488 & 1.485 \\
3.280 & 1.218 & 1.737 & 1.789 \\
4.110 & 1.345 & 1.946 & 2.067 \\
4.520 & 1.542 & 2.193 & 2.357 \\
4.980 & 1.701 & 2.404 & 2.607 \\
5.890 & 1.876 & 2.672 & 2.929 \\
\hline
\end{tabular}



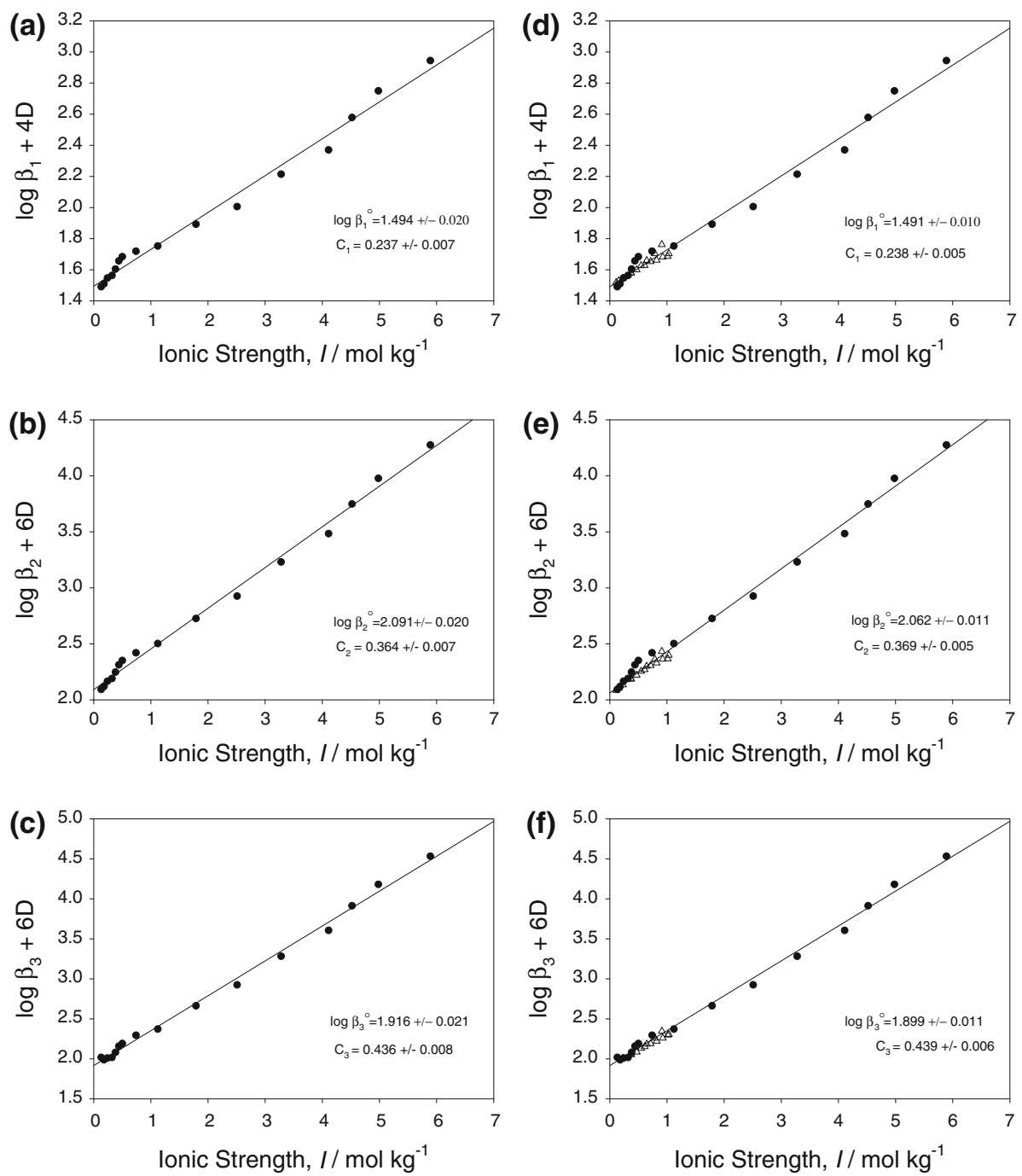

Fig. 3 Formation constants obtained using averaged molar absorptivities: a-c Luo and Millero (2007); d-f combined data: filled circle-Luo and Millero (2007—revised), triangle-Byrne and Miller (1984)

are in much better agreement with the results of the overall IUPAC data collection (first column of Table 1) and the other three component datasets (next three columns of Table 1) than are the original (subset) results of Luo and Millero (last column of Table 1). This improvement is directly attributable to a reassessment of the molar absorbance characteristics that were obtained in the original analysis of Luo and Millero (2007).

The result obtained for $\log _{\mathrm{Cl}} \beta_{1}^{0}$ (Eq. 11) is in good agreement with M63 and B82 (Table 1 ) but in poor agreement $\left(\Delta \log _{\mathrm{Cl}} \beta_{1}^{0} \sim 0.17\right)$ with the result derived from the eight papers reporting experiments at a single ionic strength (IUPAC8s). The result obtained for $\log _{\mathrm{Cl}} \beta_{2}^{0}$ (Eq. 12) is smaller than the $\log _{\mathrm{Cl}} \beta_{2}^{0}$ results of M63 and B82 by about $0.14 \log$ units and differs from the IUPAC8s result by only 0.06 units. The result obtained for $\log$ 
Table 4 Results for $\log _{\mathrm{Cl}} \beta_{\mathrm{n}}$ at 0.7 molal ionic strength and $25^{\circ} \mathrm{C}$ obtained from various data sets

\begin{tabular}{lllr}
\hline & BM84 + LM07r & M63 & B82 \\
\hline $\log _{\mathrm{Cl}} \beta_{1}$ & 0.901 & 0.863 & 0.862 \\
$\log \beta_{\mathrm{Cl}} \beta_{2}$ & 1.185 & 1.251 & 1.218 \\
$\log \mathrm{Cl} \beta_{3}$ & 1.071 & 1.234 & 1.076 \\
\hline
\end{tabular}

BM84 + LM07r Byrne and Miller (1984) + Luo and Millero (2007-revised)

M63 Mironov et al. (1963)

B82 Bendiab et al. (1982)

${ }_{\mathrm{Cl}} \beta_{3}^{0}$ (Eq. 13) is smaller than the results of M63 and B82 by 0.13 to $0.25 \log$ units and is smaller than the IUPAC8s result by $0.6 \log$ units. Thus, observed differences between predicted $\log { }_{\mathrm{Cl}} \beta_{n}^{0}$ values are largest for $\log { }_{\mathrm{Cl}} \beta_{3}^{0}$ and smallest for $\log { }_{\mathrm{Cl}} \beta_{2}^{0}$. The quality of formation constant determinations can be meaningfully assessed via examinations of stepwise stability constant behavior. The stepwise formation constant behavior of IUPAC8s (Table 1) is especially irregular, indicating that the data used to produce these results are less coherent than the results used to generate the characterizations shown in columns M63 and B82. If the formation constant results given in Eqs. 1-3 are expressed as stepwise formation constants $\left({ }_{\mathrm{Cl}} K_{n}^{0}\right)$,

$$
\begin{gathered}
\mathrm{Cl}_{1} \mathrm{~K}_{1}^{0}={ }_{\mathrm{Cl}} \beta_{1}=\left[\mathrm{PbCl}^{+}\right]\left[\mathrm{Pb}^{2+}\right]^{-1}\left[\mathrm{Cl}^{-}\right]^{-1} \\
\mathrm{Cl}_{2} \mathrm{~K}_{2}^{0}={ }_{\mathrm{Cl}} \beta_{2} /{ }_{\mathrm{Cl}} \beta_{1}=\left[\mathrm{PbCl}_{2}^{0}\right]\left[\mathrm{PbCl}^{+}\right]^{-1}\left[\mathrm{Cl}^{-}\right]^{-1} \\
{ }_{\mathrm{Cl}} \mathrm{K}_{3}^{0}={ }_{\mathrm{Cl}} \beta_{3} /{ }_{\mathrm{Cl}} \beta_{2}=\left[\mathrm{PbCl}_{3}^{-}\right]\left[\mathrm{PbCl}_{2}^{0}\right]^{-1}\left[\mathrm{Cl}^{-}\right]^{-1},
\end{gathered}
$$

the results in Eqs. 11-13 and columns B82 and M63 of Table 1 indicate a highly consistent stepwise formation constant behavior:

$$
\begin{gathered}
-0.92 \leq \log _{\mathrm{Cl}} \mathrm{K}_{2}^{0} /{ }_{\mathrm{Cl}} \mathrm{K}_{1}^{0} \leq-0.82 \text { and } \\
-0.87 \leq \log _{\mathrm{Cl}} \mathrm{K}_{3}^{0} /{ }_{\mathrm{Cl}} \mathrm{K}_{2}^{0} \leq-0.73 .
\end{gathered}
$$

In contrast, the results in column IUPAC8s (Table 1) indicate that $\log _{\mathrm{Cl}} \mathrm{K}_{2}^{0} /{ }_{\mathrm{Cl}} \mathrm{K}_{1}^{0}=$ -1.32 and $\log { }_{\mathrm{Cl}} \mathrm{K}_{3}^{0} / \mathrm{Cl}_{2} \mathrm{~K}_{2}^{0}=0.17$, with ${ }_{\mathrm{Cl}} \mathrm{K}_{3}^{0}$ being even larger than ${ }_{\mathrm{Cl}} \mathrm{K}_{2}^{0}$. This stepwise formation constant behavior is sufficiently unusual that the results summarized in column IUPAC8s, which were obtained by combining the results reported in eight different publications, should be viewed with skepticism.

Comparisons of the results given in Eqs. 11-13 with the B82 and M63 results (Table 1) indicate that while the $\log _{\mathrm{Cl}} \beta_{n}^{0}$ results produced by BM84 + LM07r are somewhat smaller, the $C_{n}$ results are consistently larger. As a result of these differences, Eqs. 11-13 predict a somewhat smaller extent of $\mathrm{Pb}$ (II) complexation at low ionic strength than do the data of Mironov et al. (1963) and Bendiab et al. (1982), but a substantially larger extent of complexation at high ionic strength. Formation constants appropriate to seawater at $25.0^{\circ} \mathrm{C}$ obtained by combining the data of Byrne and Miller (1984) and Luo and Millero (2007revised) are compared in Table 4 with the results obtained via analyses of the data of Mironov et al. (1963) and Bendiab et al. (1982).

The combined results of Byrne and Miller (1984) + Luo and Millero (2007-revised) are in close agreement with the $\mathrm{B} 82$ results. Differences in $\log _{\mathrm{Cl}} \beta_{\mathrm{n}}$ range between 0.005 and 0.039. Differences between BM84 + LM07r and M63 are somewhat larger: 0.038 for 
$\log _{\mathrm{Cl}} \beta_{1}, 0.066$ for $\log _{\mathrm{Cl}} \beta_{2}$, and 0.163 in the case of $\log { }_{\mathrm{Cl}} \beta_{3}$. The range of values for $\log$ ${ }_{\mathrm{Cl}} \beta_{1}$ and $\log _{\mathrm{Cl}} \beta_{2}$ in Table 4 is small, indicating that there are no major uncertainties in the relative concentrations of $\mathrm{Pb}^{2+}, \mathrm{PbCl}^{+}$, and $\mathrm{PbCl}_{2}^{0}$ in seawater. In contrast, Table 4 shows that predictions involving the contributions of $\mathrm{PbCl}_{3}^{-}$to lead speciation in seawater are strongly influenced by choices in available stability constant data. This potential problem should be addressed in future studies. However, with respect to this potential uncertainty, it should be noted that the regression shown in Eq. 13 is based on a very large set of data, and Fig. $3 \mathrm{f}$ shows that the results of the two independent investigations (Byrne and Miller 1984, and Luo and Millero 2007—revised) are in very close accord. As such, we regard the results shown in the first column of Table 4 as preferred estimates for $\mathrm{Pb}$ (II) chloride formation constants appropriate to seawater.

Acknowledgments This work was supported by Award OCE-0927108 from the National Science Foundation. FJM wishes to acknowledge the Oceanographic Section of the National Science Foundation for supporting his Marine Physical Chemistry studies.

Open Access This article is distributed under the terms of the Creative Commons Attribution Noncommercial License which permits any noncommercial use, distribution, and reproduction in any medium, provided the original author(s) and source are credited.

\section{Appendix}

See Tables 5, 6, 7, 8 .

Table 5 Formation constants of $\mathrm{Pb}-\mathrm{Cl}$ complexation in $\mathrm{HCl}-\mathrm{HClO}_{4}$ media, derived from data of Byrne and Miller (1984)

\begin{tabular}{lllll}
\hline Ionic strength & Medium & $\log \beta_{1}$ & $\log \beta_{2}$ & $\log \beta_{3}$ \\
\hline 0.116 & $0.116 \mathrm{HCl}$ & $1.046 \pm 0.003$ & $1.365 \pm 0.019$ & \\
0.258 & $0.258 \mathrm{HCl}$ & $0.967 \pm 0.002$ & $1.270 \pm 0.003$ & $1.144 \pm 0.033$ \\
0.458 & $0.458 \mathrm{HCl}$ & $0.914 \pm 0.002$ & $1.190 \pm 0.003$ & $1.058 \pm 0.009$ \\
0.568 & $0.568 \mathrm{HCl}$ & $0.910 \pm 0.002$ & $1.185 \pm 0.002$ & $1.065 \pm 0.005$ \\
0.607 & $0.301 \mathrm{HCl}+0.306 \mathrm{HClO}_{4}$ & $0.896 \pm 0.001$ & $1.176 \pm 0.003$ & $1.068 \pm 0.019$ \\
0.710 & $0.301 \mathrm{HCl}+0.409 \mathrm{HClO}_{4}$ & $0.893 \pm 0.001$ & $1.174 \pm 0.002$ & $1.080 \pm 0.016$ \\
0.815 & $0.301 \mathrm{HCl}+0.514 \mathrm{HClO}_{4}$ & $0.891 \pm 0.001$ & $1.175 \pm 0.002$ & $1.101 \pm 0.014$ \\
0.920 & $0.301 \mathrm{HCl}+0.619 \mathrm{HClO}_{4}$ & $0.889 \pm 0.001$ & $1.179 \pm 0.002$ & $1.101 \pm 0.012$ \\
1.027 & $0.301 \mathrm{HCl}+0.726 \mathrm{HClO}_{4}$ & $0.898 \pm 0.003$ & $1.189 \pm 0.005$ & $1.126 \pm 0.027$ \\
0.707 & $0.707 \mathrm{HCl}$ & $0.924 \pm 0.001$ & $1.199 \pm 0.001$ & $1.099 \pm 0.002$ \\
0.750 & $0.750 \mathrm{HCl}$ & $0.944 \pm 0.001$ & $1.220 \pm 0.001$ & $1.126 \pm 0.001$ \\
0.805 & $0.805 \mathrm{HCl}$ & $0.924 \pm 0.002$ & $1.200 \pm 0.001$ & $1.117 \pm 0.002$ \\
0.846 & $0.846 \mathrm{HCl}$ & $0.857 \pm 0.003$ & $1.139 \pm 0.002$ & $1.062 \pm 0.003$ \\
0.846 & $0.846 \mathrm{HCl}$ & $0.946 \pm 0.004$ & $1.223 \pm 0.003$ & $1.150 \pm 0.004$ \\
0.942 & $0.942 \mathrm{HCl}$ & $0.899 \pm 0.008$ & $1.177 \pm 0.005$ & $1.115 \pm 0.006$ \\
0.990 & $0.990 \mathrm{HCl}$ & $0.877 \pm 0.010$ & $1.158 \pm 0.005$ & $1.103 \pm 0.006$ \\
1.010 & $1.010 \mathrm{HCl}$ & $0.874 \pm 0.012$ & $1.156 \pm 0.006$ & $1.109 \pm 0.007$ \\
\hline
\end{tabular}

Data are in $\mathrm{mol} \mathrm{kg}^{-1}$ at $25^{\circ} \mathrm{C}$ 
Table 6 Formation constants of $\mathrm{Pb}-\mathrm{Cl}$ complexation in $\mathrm{NaCl}-\mathrm{NaClO}_{4}$ media, derived from data of Byrne and Miller (1984)

\begin{tabular}{lllll}
\hline Ionic strength & Medium & $\log \beta_{1}$ & $\log \beta_{2}$ & $\log \beta_{3}$ \\
\hline 0.112 & $0.112 \mathrm{NaCl}$ & $1.062 \pm 0.003$ & $1.402 \pm 0.019$ & \\
0.156 & $0.156 \mathrm{NaCl}$ & $1.022 \pm 0.002$ & $1.345 \pm 0.007$ & \\
0.230 & $0.230 \mathrm{NaCl}$ & $0.975 \pm 0.002$ & $1.279 \pm 0.004$ & $1.151 \pm 0.061$ \\
0.372 & $0.372 \mathrm{NaCl}$ & $0.926 \pm 0.003$ & $1.208 \pm 0.004$ & $1.075 \pm 0.018$ \\
0.372 & $0.372 \mathrm{NaCl}$ & $0.929 \pm 0.003$ & $1.210 \pm 0.004$ & $1.090 \pm 0.017$ \\
0.470 & $0.470 \mathrm{NaCl}$ & $0.908 \pm 0.003$ & $1.183 \pm 0.003$ & $1.049 \pm 0.011$ \\
0.609 & $0.305 \mathrm{NaCl}+0.304 \mathrm{NaClO}_{4}$ & $0.893 \pm 0.001$ & $1.167 \pm 0.003$ & $1.050 \pm 0.021$ \\
0.714 & $0.306 \mathrm{NaCl}+0.407 \mathrm{NaClO}_{4}$ & $0.891 \pm 0.001$ & $1.165 \pm 0.003$ & $1.047 \pm 0.019$ \\
0.819 & $0.307 \mathrm{NaCl}+0.512 \mathrm{NaClO}_{4}$ & $0.876 \pm 0.001$ & $1.153 \pm 0.003$ & $1.045 \pm 0.018$ \\
0.926 & $0.308 \mathrm{NaCl}+0.618 \mathrm{NaClO}_{4}$ & $0.878 \pm 0.001$ & $1.155 \pm 0.002$ & $1.052 \pm 0.017$ \\
1.033 & $0.308 \mathrm{NaCl}+0.724 \mathrm{NaClO}_{4}$ & $0.881 \pm 0.001$ & $1.164 \pm 0.002$ & $1.070 \pm 0.012$ \\
0.547 & $0.547 \mathrm{NaCl}$ & $0.910 \pm 0.003$ & $1.180 \pm 0.003$ & $1.058 \pm 0.007$ \\
0.646 & $0.646 \mathrm{NaCl}$ & $0.914 \pm 0.003$ & $1.183 \pm 0.002$ & $1.067 \pm 0.004$ \\
0.788 & $0.788 \mathrm{NaCl}$ & $0.925 \pm 0.002$ & $1.194 \pm 0.001$ & $1.092 \pm 0.002$ \\
0.910 & $0.910 \mathrm{NaCl}$ & $0.959 \pm 0.005$ & $1.229 \pm 0.003$ & $1.143 \pm 0.004$ \\
1.015 & $1.015 \mathrm{NaCl}$ & $0.866 \pm 0.013$ & $1.136 \pm 0.007$ & $1.067 \pm 0.008$ \\
\hline $0.19 a$ & & & &
\end{tabular}

Data are in $\mathrm{mol} \mathrm{kg}^{-1}$ at $25^{\circ} \mathrm{C}$

Table 7 Formation constants of $\mathrm{Pb}-\mathrm{Cl}$ complexation in $\mathrm{CaCl}_{2}$ media, derived from data of Byrne and Miller (1984)

\begin{tabular}{|c|c|c|c|c|}
\hline Ionic strength & Medium & $\log \beta_{1}$ & $\log \beta_{2}$ & $\log \beta_{3}$ \\
\hline 0.117 & $0.0357 \mathrm{CaCl}_{2}$ & $1.064 \pm 0.004$ & & \\
\hline 0.223 & $0.0710 \mathrm{CaCl}_{2}$ & $0.984 \pm 0.002$ & $1.276 \pm 0.009$ & \\
\hline 0.359 & $0.1163 \mathrm{CaCl}_{2}$ & $0.923 \pm 0.001$ & $1.190 \pm 0.004$ & $1.043 \pm 0.061$ \\
\hline 0.453 & $0.1477 \mathrm{CaCl}_{2}$ & $0.894 \pm 0.002$ & $1.150 \pm 0.004$ & $1.000 \pm 0.032$ \\
\hline 0.527 & $0.1725 \mathrm{CaCl}_{2}$ & $0.877 \pm 0.002$ & $1.124 \pm 0.004$ & $0.979 \pm 0.021$ \\
\hline 0.622 & $0.2039 \mathrm{CaCl}_{2}$ & $0.862 \pm 0.003$ & $1.104 \pm 0.004$ & $0.962 \pm 0.014$ \\
\hline 0.759 & $0.2495 \mathrm{CaCl}_{2}$ & $0.847 \pm 0.003$ & $1.084 \pm 0.003$ & $0.945 \pm 0.009$ \\
\hline 0.830 & $0.2734 \mathrm{CaCl}_{2}$ & $0.845 \pm 0.003$ & $1.083 \pm 0.003$ & $0.951 \pm 0.008$ \\
\hline 0.881 & $0.2902 \mathrm{CaCl}_{2}$ & $0.848 \pm 0.002$ & $1.084 \pm 0.002$ & $0.958 \pm 0.005$ \\
\hline 0.931 & $0.3069 \mathrm{CaCl}_{2}$ & $0.839 \pm 0.003$ & $1.074 \pm 0.002$ & $0.951 \pm 0.005$ \\
\hline 0.974 & $0.3214 \mathrm{CaCl}_{2}$ & $0.826 \pm 0.003$ & $1.060 \pm 0.002$ & $0.935 \pm 0.005$ \\
\hline 0.974 & $0.3214 \mathrm{CaCl}_{2}$ & $0.865 \pm 0.003$ & $1.097 \pm 0.003$ & $0.984 \pm 0.006$ \\
\hline
\end{tabular}

Data are in $\mathrm{mol} \mathrm{kg}^{-1}$ at $25^{\circ} \mathrm{C}$ 
Table 8 Formation constants of $\mathrm{Pb}-\mathrm{Cl}$ complexation in $\mathrm{MgCl}_{2}$ media, derived from data of Byrne and Miller (1984)

\begin{tabular}{lllll}
\hline Ionic strength & Medium & $\log \beta_{1}$ & $\log \beta_{2}$ & $\log \beta_{3}$ \\
\hline 0.113 & $0.0345 \mathrm{MgCl}_{2}$ & $1.067 \pm 0.004$ & & \\
0.257 & $0.0824 \mathrm{MgCl}_{2}$ & $0.969 \pm 0.002$ & $1.251 \pm 0.006$ & \\
0.458 & $0.1493 \mathrm{MgCl}_{2}$ & $0.899 \pm 0.002$ & $1.152 \pm 0.003$ & $1.002 \pm 0.027$ \\
0.573 & $0.1877 \mathrm{MgCl}_{2}$ & $0.881 \pm 0.002$ & $1.134 \pm 0.003$ & $0.993 \pm 0.014$ \\
0.707 & $0.2322 \mathrm{MgCl}_{2}$ & $0.850 \pm 0.003$ & $1.091 \pm 0.004$ & $0.943 \pm 0.013$ \\
0.758 & $0.2494 \mathrm{MgCl}_{2}$ & $0.860 \pm 0.002$ & $1.095 \pm 0.003$ & $0.953 \pm 0.008$ \\
0.854 & $0.2814 \mathrm{MgCl}_{2}$ & $0.852 \pm 0.003$ & $1.097 \pm 0.003$ & $0.957 \pm 0.007$ \\
0.951 & $0.3136 \mathrm{MgCl}_{2}$ & $0.858 \pm 0.002$ & $1.089 \pm 0.002$ & $0.961 \pm 0.004$ \\
0.999 & $0.3296 \mathrm{MgCl}_{2}$ & $0.859 \pm 0.002$ & $1.095 \pm 0.002$ & $0.966 \pm 0.005$ \\
\hline
\end{tabular}

Data are in $\mathrm{mol} \mathrm{kg}^{-1}$ at $25^{\circ} \mathrm{C}$

\section{References}

Bendiab H, Meullemeestre MJ, Schwing MJ, Vierling F (1982) Thermodynamic constants and electronicspectra of lead(II) chloro-complexes in aqueous solutions. J Chem Res (M) 1982:2718-2745

Byrne RH, Miller WL (1984) Medium composition dependence of lead (II) complexation by chloride ion. Am J Sci 284:79-94

Byrne RH, Young RW, Miller WL (1981) Lead chloride complexation using ultraviolet molar absorptivity characteristics. J Sol Chem 10:234-251

Luo Y, Millero FJ (2007) Stability constants for the formation of lead chloride complexes as a function of temperature and ionic strength. Geochim Cosmochim Acta 71:326-334

Mironov V, Kulba F, Fedorov V, Tikhomirov O (1963) The influence of anion background on the formation of chloride and nitrate complexes of lead (II). Zh Neorg Khim 8(11):2536-2540

Powell KJ, Brown PL, Byrne RH, Gajda T, Hefter G, Leuz K-A, Sjoberg S, Wanner H (2009) Chemical speciation of environmentally significant metals with inorganic ligands. Part 3: the $\mathrm{Pb}^{+}+\mathrm{OH}^{-}, \mathrm{Cl}^{-}$, $\mathrm{CO}_{3}{ }^{2-}, \mathrm{SO}_{4}{ }^{2-}$, and $\mathrm{PO}_{4}{ }^{3-}$ systems (IUPAC Technical Report). Pure Appl Chem 81(12):2425-2476 